\title{
Friction and Wear of Polymer Composites Filled by Nano-Particles: A Review
}

\author{
Ayman A. Aly ${ }^{*}$, El-Shafei B. Zeidan, AbdAllah A. Alshennawy, Aly A. El-Masry, Wahid A. Wasel \\ Mechatronics Section, Department of Mechanical Engineering, Faculty of Engineering, \\ Taif University, Taif, Saudi Arabia \\ Email: "draymanelnaggar@yahoo.com
}

Received November 14, 2011; revised December 19, 2011; accepted January 10, 2012

\begin{abstract}
Composites formed by adding nano-scale particles to a polymer matrix results in improving electrical, mechanical, and thermal properties of the composite. Good tribological properties can be obtained for polymers filled with nano-scale fillers compared to that filled with micro-scale particles. The friction and wear resistance of these composites is found to increase with increasing filler concentration. It is also possible to use multi-functional fillers to develop high performance composites which cannot be achieved by using a single filler.
\end{abstract}

Keywords: Friction; Wear; Polymer Composites; Nano-Particles

\section{Introduction}

In the past few decades, researchers and engineers interest has been shifting from monolithic materials to reinforced polymeric materials. These composite materials now dominate the pharmaceutical, aerospace, leisure, automotive, construction, and sporting industries [1-3].

A polymer nano-composite is defined as a composite material with a polymer matrix and filler particles that have at least one dimension less than $100 \mathrm{~nm}$. These engineering composites are desired due to their low density, high corrosion resistance, ease of fabrication and low cost [4-7]. Glass fibers are the most widely used to reinforce plastics due to their good mechanical properties and low cost. Various kinds of polymers and polymer matrix composites reinforced with metal particles have a wide range of industrial applications such as heaters, electrodes, actuators etc. [8]. When silica nano-particles are added to a polymer matrix to form a composite, they play an important role in improving electrical, mechaniccal, and thermal properties of composites [3,9]. The inclusion of inorganic fillers into polymers for commercial applications is primarily aimed at the cost reduction and stiffness improvement [10].

Polymer composites can be fabricated by the incorporation of inorganic reinforcements into the polymer matrix. The properties of the resulting polymer composites depend on the characteristics, the dimensions, and the shapes of the inorganic fillers, and also on the interfacial bonding strength. It is proposed that with decreasing

\footnotetext{
*Corresponding author.
}

filler dimensions or increasing filler content a significant improve in the contact area between the filler and matrix, and in turn it would greatly and effectively improve the transfer of the load between the fillers and the polymer matrix [11]. The inorganic nano-fillers, ranging from 1 to $50 \mathrm{~nm}$, were successfully incorporated into the polymeric matrix to strengthen and improve the ductile polymer to be more stiff and resistant for abrasion [12,13].

The inclusion of the ceramic nano-filler into the more flexible and lower thermal resistance polymer can substantially improve its stiffness and thermal stability [1417]. The nano-sized silica or alumina particles without any chemical modification were incorporated into the PEEK polymer. It appears that there are occasional clustering occurrences for two to five nano-particles to cluster or align together, the majority of the nano-particles were seen to disperse semi-homogeneously in the polyetheretherketone (PEEK) matrix [18].

With the booming of nano-phased materials in the recent years, attempts are being made to develop nanoparticle filled-polymer composites with improved tribological performance of the materials. It is expected that good tribological properties can be obtained for the polymers filled with nano-scale fillers compared to those filled with micro-scale particles $[19,20]$. Due to their lower strength and stiffness compared with synthetic fibers, natural fibers use in polymer composites has been limited to non-tribological applications. Very little information concerning the tribological performance of natural fiber reinforced composite materials has been reported [21]. 
Polytetrafluoroethylene (PTFE) exhibits many desirable tribological characteristics, including high melting temperature, low friction, and chemical inertness. PTFE is an excellent solid lubricant and used commonly in bearing and seals applications [22] Unfortunately, PTFE exhibits high wear rate under normal friction conditions, which limits its application fields. Therefore, many kinds of PTFE-based composites have been produced to improve the wear resistance of PTFE [23,24]. It was found that some micro-scale inorganic fillers showed distinct effect on the friction and wear behaviors of PTFE composites [25].

The present paper presents a survey on nano-filler polymer-based composites with improved mechanical properties for low friction and low wear applications. The effect of filler particle size is summarized. Then the effect of chemical surface modification and multi functional fillers is reviewed. Finally some conclusions are drawn.

\section{Effect of Nano-Filler Particle Size and Ratio}

The shape, size, volume fraction, and specific surface area of added particles have been found to affect mechanical properties of the composites greatly. Currently, many studies have focused on how single-particle size affects mechanical properties of the composites [26-29]. Hoshino et al. [26] discussed the effects of size and shape of silica particle on the strength and fracture toughness based on particle-matrix adhesion and they found an increase of the flexural and tensile strength as specific surface area of particles increased. Yamamoto et al. [27] reported that the structure and shape of silica particle have significant effects on the mechanical properties such as fatigue resistance, tensile and fracture properties.

The effects of inorganic nanometer particles, such as $\mathrm{SiC}, \mathrm{SiO}_{2}, \mathrm{Si}_{3} \mathrm{~N}_{4}$ and $\mathrm{ZrO}_{2}$ on the tribological properties of some polymers have been studied. Li et al. [24] reported that filling nanometer $\mathrm{ZnO}$ to PTFE could greatly reduce the wear of this polymer and the best anti-wear property was obtained with the composite containing 15 vol\% nanometer $\mathrm{ZnO}$, but the friction coefficient of nano-composite was higher than that of the unfilled PTFE. Sawyer et al. [25] investigated the tribological properties of PTFE composites filled with $40 \mathrm{~nm} \mathrm{Al}_{2} \mathrm{O}_{3}$, and they found that the friction coefficient of the composite increased slightly compared to the unfilled sample and the wear resistance increased monotonically with increasing filler concentration.

Wang et al. [30-36] have filled PEEK with various weight fractions of $\mathrm{SiC}, \mathrm{Si}_{3} \mathrm{~N}_{4}, \mathrm{SiO}_{2}$, and $\mathrm{ZrO}_{2}$. The addition of the filler in fractions less than $10 \%$ by weight improved the wear resistance and reduced the friction coefficient. The improved wear and friction is attributed to two factors: the smoothing of the steel counterface, and the development of a transfer film. Schwartz and Bahadur [37] filled polyphenylene sulfide (PPS) with alumina nano-particles. Examination of these samples with scanning electron microscopy showed good dispersion of filler particles in the PPS matrix. Wear tests were performed on a four stations pin-on-disk tribometer. The roughness of the counter face was varied. It was postulated that this parameter directly relates to the development of the transfer film on the counter face; the rougher surface facilitates transfer film growth. Similar to the previous studies, maximum wear resistance was found at weight percentages below 10 .

As the percentage of filler increased above this optimum, the composite material experienced more wear than the unfilled counterpart. Unlike the previous work with PEEK, the coefficient of friction increased monotonically with increasing filler concentrations. Li et al. [24] filled PTFE with nano particles of $\mathrm{ZnO}$. Wear resistance was improved by nearly two orders of magnitude with a maximum wear resistance at $\mathrm{ZnO}$ concentrations of roughly $15 \%$ by volume. In that study, the friction coefficient of the nano-composite was higher than the unfilled PTFE. Petrovicova et al. [38] filled Nylon 11 with silica. Wear resistance increased with increasing concentrations of nanoscale silica up to $15 \%$ by volume. They found that the friction coefficient of the nano-composite was lower than that of the unfilled Nylon. Avella et al. [39] filled polymethylmethacrylate (PMMA) with nano-scale $\mathrm{CaCO}_{3}$. The abrasion resistance increased as the filler content was increased, improving by a factor of $2 \%$ with $3 \%$ $\mathrm{CaCO}_{3}$ by weight. Yu et al. [40] filled polyoxymethylene (POM) with micrometer and submicron copper particles. The nano-composite had less wear and a lower coefficient of friction than the composites filled with micrometer sized particles of copper and the unfilled POM. It was hypothesized that the increased surface area of the submicron copper filler particles improved the bonding strength at the filler/matrix interface. In Figure 1, the reported wear-rates of the nano-composites are each normalized by the reported wear-rate of the unfilled matrix and plotted versus the volume fraction of filler particles. In Table 1. the wear-rate for the most wear-resistant formulation of each nano-composite is given [25].

This compilation of data showed that the optimum concentrations of nanometer sized filler particles is $2 \%$ $5 \%$ by volume. A more typical optimum in polymer composites made with micrometer sized filler particles is on the order of $30 \%$. It is also shown that consistent observation that improvements in wear can be realized with polymer nano-composites. But the origin of wear resistance improvements in polymer nano-composites is an open question. 


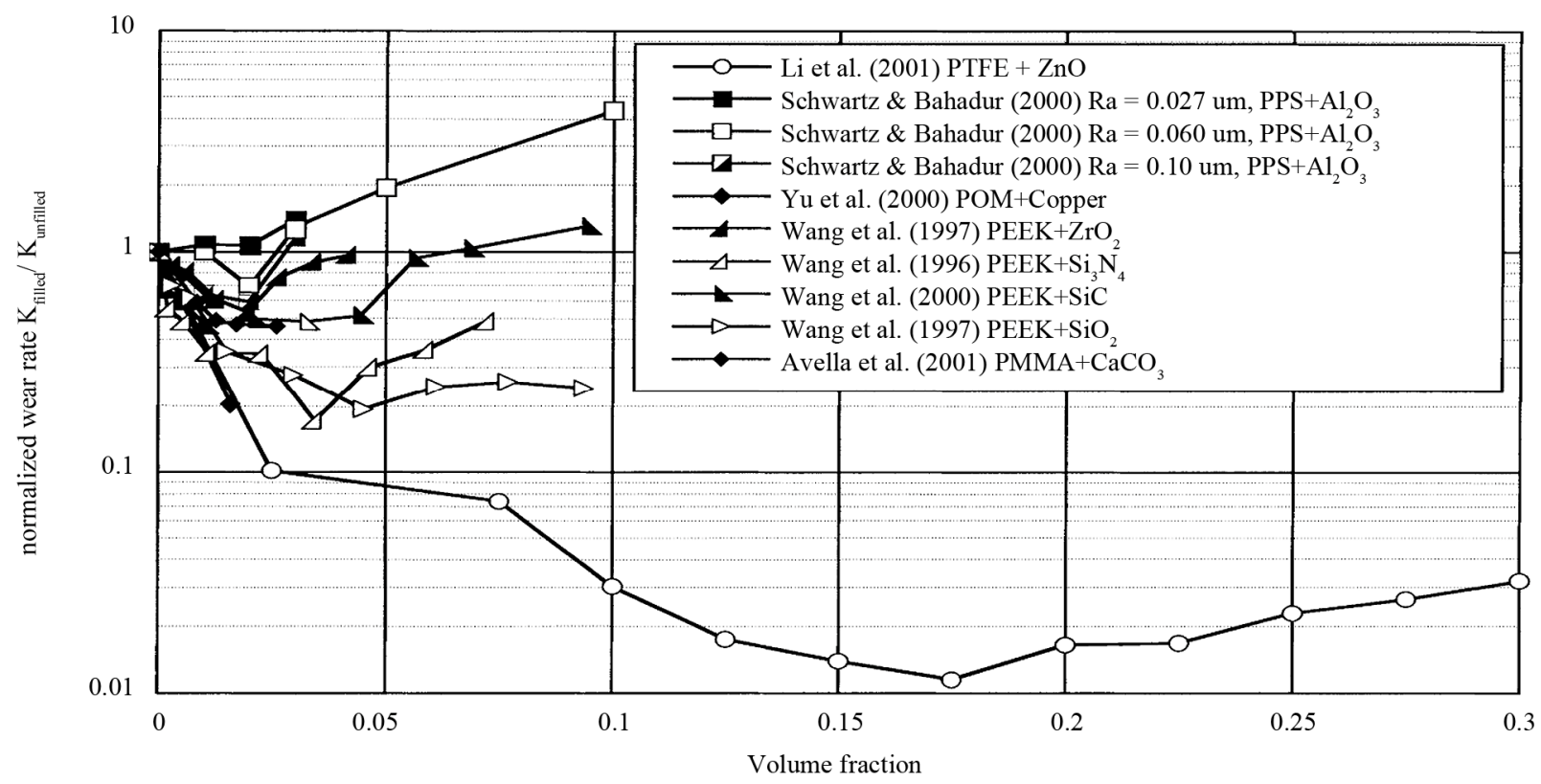

Figure 1. A plot of normalized wear improvements for polymer nano-composites as a function of filler volume fraction [25].

Table 1. A comparison of the lowest reported wear-rates for various polymer nano-composites [25].

\begin{tabular}{cc}
\hline Matrix/nano-filler & $\begin{array}{c}\text { Lowest wear-rate, } \mathrm{k} \\
\left(\times 10-6 \mathrm{~mm}^{3} / \mathrm{Nm}\right)\end{array}$ \\
\hline $\mathrm{PTEE} / \mathrm{ZnO}$ & 13 \\
$\mathrm{PPS} / \mathrm{Al}_{2} \mathrm{O}_{3}$ & 10.4 \\
$\mathrm{PEEK} / \mathrm{SiC}$ & 3.4 \\
$\mathrm{PEEK} / \mathrm{Si}_{3} \mathrm{~N}_{4}$ & 1.3 \\
$\mathrm{PEEK} / \mathrm{ZrO}_{2}$ & 3.9 \\
$\mathrm{PEEK} / \mathrm{SiO}_{2}$ & 1.4 \\
\hline
\end{tabular}

As a PTFE matrix, it has been successfully filled with nano-particles of alumina, zinca, and carbon nano-tubes. Sawyer et al. [41] used $38 \mathrm{~nm} \mathrm{Al}_{2} \mathrm{O}_{3}$ filler to improve the wear performance of PTFE, and the wear resistance of this nanocomposite increased monotonically with filler wt\%, eventually being 600 times more wear resistant than unfilled PTFE at a loading of $20 \mathrm{wt} \%$. Burris and Sawyer [42] and Li et al. [24] have found similar improvements for metal-oxide nano-composites of PTFE at high weight percents of filler. The promise of nano-composites, however, was that low weight percents could provide such improvements. This study is the first in which low weight percentage of filler particles are shown to provide over $1000 \times$ improvements in wear rate. The difference between these composites and previous nanocomposites of PTFE is that the nano-particles are irregular in shape, as opposed to the spherical shape of previous composites.

\section{Chemical Surface Modification}

Chemical surface modification is widely used to obtain a high wettability for a solid surface, a good dispersion of particles, and adhesion of fillers in composite materials [43]. Chemical surface modification can be categorized as follows:

\section{Surface modification by chemical reaction}

This type of surface modification promotes a chemical reaction between the polymer matrix and an inorganic filler to strengthen the adhesion. Two reagents are mainly used in chemical surface modification to obtain a hydrophobic surface. One example of such a reagent is an alkyl silane coupling agent and another is an alcohol [44-46].

\section{Surface modification by non-reactive modifier}

In most cases the surface of the nano-particles used for nano-particle filled polymer composites prepared by dispersive mixing for tribological applications have not been pre-treated. If no specific surface treatment is applied beforehand, the unique nano-effect of nano-particles cannot be fully brought into play. Therefore, pre-treatment of nano-particles before every experiment is necessary.

A nonreactive modifier reduces the interaction between the filler particles within agglomerates by reducing the physical attraction rather than by any chemical reaction $[47,48]$.

Stearic acid has been widely used as a non-interacting surface modifier. Modified nano-filler can easily be incorporated into a polymer matrix, resulting in a decrease in the melt viscosity and, in most cases, an improved dispersion of the nano-filler in the composite $[49,50]$. The wettability of silica nano-particles and the adhesion be- 
tween the filler and the polymer matrix were improved by modifying the silica nano-particles with stearic acid [51]. The non-reactive stearic acid reduces the interaction between the filler particles within agglomerates by reducing the physical attraction, rather than by any chemical reaction. However there has been little research related to the mechanical properties of silica nano-particle reinforced PEN composites with the modification of stearic acid.

Surface modified silica nano-particle reinforced PEN composites were melt blended to investigate the effect of stearic acid modification on the mechanical properties, crystallization behavior, and the processibility of the silica nano-particle reinforced PEN composites. The interfacial properties of the composites with stearic acid modification were quantitatively analyzed from tensile test results with various theoretical models [52].

The attempts to improve the tribological properties of pure poly-electrolyte multilayers (PEMs) have been largely focused on transforming the structure of PEMs. It was found that the load carrying capacity of the polyelectrolyte multilayer film increased and better anti-wear properties can be obtained with compositing nanoparticles [53].

Zhang et al. [54-57] have systematically studied the tribological behavior of composite Langmuir-Blodgett (LB) films consisted of organic molecule and inorganic nanoparticles, they found that the nano-particles play a key role in increasing antiwear life of LB films, enhancing the load-carrying capacity of the films. In the present years, the organic-inorganic hybrid thin films have also attracted widespread attention because of their low friction coefficient and relatively long antiwear life [58].

Nucleation and growth of $\mathrm{ZnS}$ nano-particles were achieved in a poly (diallyl dimethylammonium chloride) (PDDA)-poly(acrylic acid) (PAA) film prepared by the layer-by-layer deposition technique. It was found that $\mathrm{ZnS}$ nano-particles within PEMs possess load-carrying capacity and enhance antiwear life. Moreover, the PEMs with three reaction cycles show considerably lower friction coefficient and higher antiwear life than the PEMs with six reaction cycles [59].

Attapulgite (or palygorskite) is a clay mineral that together with sepiolite forms the group of fibrous clay minerals. The structure of attapulgite was first proposed by Bradley [60]. It finds important uses as an animal waste adsorbent, pesticide carrier, decolorizing agent, in the oil refining and pharmaceutical industries and catalyst and catalyst support [61-63]. Due to its especial layerchain structure and low price, nowadays attapulgite is receiving a great deal of attention. However, until now, not much information has been available on the friction and wear behaviors of the PTFE composite filled with nano-attapulgite.
Silica/polymer composites were found to posses unique physical, chemical and electromechanical properties, which have extensive application potential [64]. The addition of various nano-sized fillers into polymer which may cause an improvement in the tribological feature at low filler contents due to a change of the wear mechanisms were reported by Wang and Xue [65]. Su and co-workers [66] revealed the friction and wear behaviors of the resulting carbon fabric composites sliding against AISI-1045 steel in a pin-on-disk apparatus. Nanofillers, such as $\mathrm{TiO}_{2}$, $\mathrm{ZnO}, \mathrm{SiO}_{2}$ and $\mathrm{Si}_{3} \mathrm{~N}_{4}$ were reported to be effective in improving the friction and wear properties of some polymer and fabric composites $[67,68]$.

\section{Use of Multi Functional Nano-Fillers}

Integrating various functional fillers is a principal route to develop high performance composite materials which cannot be achieved by using the single filler alone [69]. Considerable attempts have been made to incorporate different additional fillers in to SFRPs in order to further improve the tribological performance. In particular, lubricating particulates such as polytetrafluoroethylene (PTFE), graphite and molybdenum disulfide $\left(\mathrm{MoS}_{2}\right)$ have been successfully used to reduce the friction coefficient and the wear rate of SFRPs [70-73]. These solid lubricants are generally helpful in developing a uniform transfer layer on the surface of metallic counterparts, which protects fibers from severe abrasive wear.

More recently, nano-sized inorganic particles have also come under consideration. For instance, Cho and Bahadur [74] reported that the addition of 2 vol\% nano$\mathrm{CuO}$ could generally enhance the wear resistance of short fiber-reinforced polyphenylene sulfide. The beneficial effect of nano-particles was attributed to the development of a thin and uniform transfer film. Zhang et al. [75] and Chang et al. [76] systematically studied the effect of nano- $\mathrm{TiO}_{2}$ on short fiber-reinforced epoxy under different loading conditions. They found that the addition of 5 vol\% nano- $\mathrm{TiO}_{2}$ could significantly reduce the friction coefficient and the wear rate of epoxy composites than filling only with traditional fillers. The reduction was more pronounced at high $p v$ (the product of pressure and velocity) conditions. The rolling effect of nano-particles was proposed to explain the low friction and wear loss of the nano-composites.

Guo et al. [77] used surface modified nano- $\mathrm{SiO}_{2}$ filler to enhance the tribo-properties of epoxy composites filled with short carbon fibers. In order to improve the interface bonding between nanoparticles and the polymeric matrix, the nanoparticles were pretreated by graft polymerization. The additional nanoparticles ( $4 \mathrm{wt} \%$ ) proved to be useful in enhancing the wear resistance and reducing the friction coefficient of the SFRPs. This improvement mecha- 
nisms of nano-particles could be caused by the increased strength of the matrix and better proper- ties of the transfer film. These results have clearly shown that the addition of nano-particles is potentially useful to improve the tribological performance of SFRPs, even at a relatively low content. Nevertheless, the improvement mechanisms using nano-particles have not been deeply understood, although the pioneer researchers have addressed a number of significant factors affecting the wear behavior of these materials.

\section{Conclusion}

A survey study has been conducted and showed that the interest in polymer-based composites for technical applications, in which low friction and low wear, is increaseing. The survey showed that there is a significant improvement in mechanical properties of the composite due to the addition of the nano-particles. Many types of nanofilling martials, including $\mathrm{SiC}, \mathrm{Si}_{3} \mathrm{~N}_{4}, \mathrm{SiO}_{2}, \mathrm{ZrO}_{2}, \mathrm{ZnO}$, $\mathrm{CaCO}_{3}, \mathrm{Al}_{2} \mathrm{O}_{3}, \mathrm{TiO}_{2}$, and nano-CuO, have been used to different types of polymers such as PEEK; PMMA; PTFE and epoxy. The mechanical properties which have been improved include fatigue resistance, fracture toughness, tensile strength, wear resistance, and friction coefficient. From the results of the conducted studies there is a considerable increase in wear resistance and decrease in the coefficient of friction. The change of wear resistance and friction coefficient depends on the size and volume fraction of the nano-filling materials. It is also possible to use multi functional fillers to develop high performance composite materials which cannot be achieved by using a single filler.

\section{Acknowledgements}

This study is supported by Taif University under a contract No. 1-432-1171. The University is highly acknowledged for its financial support.

\section{REFERENCES}

[1] A. S. Manmode, D. M. Sakarkar and N. M. Mahajan, "Nanoparticles-Tremendous Therapeutic Potential: A Revier," International Journal of PharmTech Research, Vol. 1, No. 4, 2009, pp. 1020-1027.

[2] P. Ayak, S. K. Sahoo, A. Behera, P. K. Nanda, P. L. Nayak and B. C. Guru, "Synthesis and Characterization of Soy Protin Isolate/MMT Nanocomposite Film for the Control Release of the Drug Ofloxacin,” World Journal of Nano Science and Engineering, Vol. 1, No. 2, 2011, pp. 27-36. doi:10.4236/wjnse.2011.12005

[3] L. E. Nielsen and R. F. Landel, "Mechanical Properties of Polymers and Composites,” 2nd Edition, Marcel Deckker, New York, 1994.

[4] S. Nikkeshi, M. Kudo and T. Masuko, "Dynamic Viscoe- lastic Properties and Thermal Properties of Powder-Epoxy Resin Composites,” Journal of Applied Polymer Science, Vol. 69, No. 13, 1998, pp. 2593-2598. doi:10.1002/(SICI)1097-4628(19980926)69:13<2593::AI D-APP9>3.0.CO;2-5

[5] K. Zhu and S. Schmauder, "Prediction of the Failure Properties of Short Fiber Reinforced Composites with Metal and Polymer Matrix,” Computational Materials Science, Vol. 28, No. 3-4, 2003, pp. 743-748.

doi:10.1016/j.commatsci.2003.08.028

[6] I. H. Tavman, "Thermal and Mechanical Properties of Copper Powder Filled Polyethylene Composites," Powder Technology, Vol. 91, No. 1, 1997, pp. 63-67. doi:10.1016/S0032-5910(96)03247-0

[7] T. Ahmad and O. Mamat, "The Development and Characterization of Zirconia-Silica Sand Nanoparticles Composites," World Journal of Nano Science and Engineering, Vol. 1, No. 1, 2011, pp. 7-14. doi:10.4236/wjnse.2011.11002

[8] K. Jung-il, P. H. Kang and Y .C. Nho, "Positive Temperature Coefficient Behavior of Polymer Composites Having a High Melting Temperature,” Journal of Applied Polymer Science, Vol. 92, No. 1, 2004, pp. 394-401. doi:10.1002/app.20064

[9] S. T. Peters, "Handbook of Composites," 2nd Edition, Chapman and Hall, London, 1998.

[10] R. N. Rothon, "Mineral Fillers in Thermoplastics I: Raw Materials and Processing," Springer, Berlin, 1999.

[11] M. Sumita, T. Shizuma, K. Miyasaka and K. Ishikawa, "Effect of Reducible Properties of Temperature, Rate of Strain, and Filler Content on the Tensile Yield Stress of Nylon 6 Composites Filled with Ultrafine Particlesm," Journal of Macromolecular Science: Physics, Vol. B22, No. 4, 1983, pp. 601-618.

[12] Q.-H. Wang, J. Xue, W. Shen and W. Liu, “An Investigation of the Friction and Wear Properties of Nanometer $\mathrm{Si}_{3} \mathrm{~N}_{4}$ Filled PEEK,” Wear, Vol. 196, No. 1-2, 1996, pp. 82-86. doi:10.1016/0043-1648(95)06866-X

[13] Q.-H. Wang, Q. Xue, H. Liu, W. Shen and J. Xue, “The Effect of Particle Size of Nanometer $\mathrm{ZrO}_{2}$ on the Tribological Behaviour of PEEK,” Wear, Vol. 198, No. 1-2, 1996, pp. 216-219. doi:10.1016/0043-1648(96)07201-8

[14] M. C. Kuo, C. M. Tsai, J. C. Huang and M. Chen, "PEEK Composites Reinforced by Nano-Sized $\mathrm{SiO}_{2}$ and $\mathrm{Al}_{2} \mathrm{O}_{3}$ Particulates Materials,” Chemistry and Physics, Vol. 90, No. 1, 2005, pp. 185-195.

[15] T. E. Attwood, P. C. Dawson, J. L. Freeman, L. R. J. Hoy, J. B. Rose and P. A. Staniland, "Synthesis \& Properties of Polyaryletherketones,” Polymer, Vol. 22, No. 8, 1981, pp. 1096-1103. doi:10.1016/0032-3861(81)90299-8

[16] P. K. Goyal, Y. S. Negi and A. N. Tiwari, "Preparation of High Performance Composites Based on Aluminum Nitride/Poly(Ether-Ether-Ketone) and Their Properties," European Polymer Journal, Vol. 41, No. 9, 2005, p. 20342044. doi:10.1016/j.eurpolymj.2005.04.009

[17] P. Cassagnau, "Payne Effect and Shear Elasticity of Silica-Filled Polymers in Concentrated Solutions and in Molten State,” Polymer, Vol. 44, No. 8, 2003, pp. 2455- 
2462. doi:10.1016/S0032-3861(03)00094-6

[18] M. C. Kuo, J. C. Huang and M. Chena "Non-Isothermal Crystallization Kinetic Behavior of Alumina Nanoparticle Filled Poly(Etheretherketone)," Materials Chemistry and Physics, Vol. 99, No. 2-3, 2006, pp. 258-268. doi:10.1016/j.matchemphys.2005.10.021

[19] Q. H. Wang, Q. J. Xue, W. M. Liu and J. M. Chen, "The Friction and Wear Characteristics of Nanometer SiC and Polytetrafluoroethylene Filled Polyetheretherketone,” Wear, Vol. 243, No. 1-2, 2000, pp. 140-146. doi:10.1016/S0043-1648(00)00432-4

[20] C. J. Schwartz and S. Bahdur, "Studies on the Tribological Behavior and Transfer Film-Counterface Bond Strength for Polyphenylene Sulfide Filled with Nanoscale Alumina Particles,” Wear, Vol. 237, No. 2, 2000, pp. 261-273. doi:10.1016/S0043-1648(99)00345-2

[21] E. Reynaud, C. Gauthier and J. Perez, "Nanophases in Polymers,” Revue De Metallurgie, Vol. 98, 1999, pp. 169176.

[22] Q. H. Wang, Q. J. Xue and W. C. Shen, "The Friction and Wear Properties of Nanometre $\mathrm{SiO}_{2}$ Filled Polyetheretherketone,” Tribology International, Vol. 30, No. 3, 1997, 193-197. doi:10.1016/S0301-679X(96)00042-4

[23] M. Q. Zhang, M. Z. Rong, S. L. Yu, B. Wetzel and K. Friedrich, "Improvement of Tribological Performance of Epoxy by the Addition of Irradiation Crafted Nano-Ino ganic Particles," Macromolecular Materials and Engineering, Vol. 287, No. 2, 2002, 111-115. doi:10.1002/1439-2054(20020201)287:2<111::AID-MA ME111>3.0.CO;2-I

[24] F. Li, K. Hu and J. Li, "The Friction and Wear Characteristics of Nanometer ZnO Filled Polytetrafluoroethylene,” Wear, Vol. 249, No. 10-11, 2002, pp. 877-882. doi:10.1016/S0043-1648(01)00816-X

[25] W. G. Sawyer, K. D. Freudenberg, P. Bhimaraj and L. S. Schadler, "A Study on the Friction and Wear Behavior of PTFE Filled with Alumina Nanoparticles,” Wear, Vol. 254, No. 5, 2003, pp. 573-580.

[26] A. Hoshino, K. Fujioka, T. Oku, S. Nakamura, M. Suga, Y. Yamaguchi, K. Suzuki and M. Yasuhara, "Quantum dots Targeted to the Assigned Organelle in Living Cells," Microbiology and Immunology, Vol. 48, No. 12, 2004, pp. 985-994.

[27] I. Yamamoto, T. Higashihara and T. Kobayashi, "Effect of Silica-Particle Characteristics on Impact/Usual Fatigue Properties and Evaluation of Mechanical Characteristics of Silica-Particle Epoxy Resins,” JSME International Journal, Vol. 46, No. 2, 2003, pp. 145-153. doi:10.1299/jsmea.46.145

[28] W. J. Cantwell and A. C. Moloney, "Fractography and Failure Mechanisms of Polymers and Composites,” Elesvier, Ameserdam, 1994.

[29] R. J. Young and P. W. R. Beaumont, "Failure of Brittle Polymers by Slow Crack Growth: Part 3 Effect of Composition upon the Fracture of Silica Particle-Filled Epoxy resin Composites,” Journal of Materials Science, Vol. 12, No. 4, 1997, pp. 684-692.

[30] Q. Wang, Q. Xue, H. Liu, W. Shen and J. Xu, “The Effect of Particle Size of Nanometer $\mathrm{ZrO}_{2}$ on the Tribological Behaviour of PEEK," Wear, Vol. 198, No. 1-2, 1996, pp. 216-219. doi:10.1016/0043-1648(96)07201-8

[31] Q. Wang, J. Xue, W. Shen and W. Liu, “An Investigation of the Friction and Wear Properties of Nanometer $\mathrm{Si}_{3} \mathrm{~N}_{4}$ Filled PEEK,” Wear, Vol. 196, No. 1-2, 1996, pp. 82-86. doi:10.1016/0043-1648(95)06866-X

[32] Q. Wang, Q. Xue, H. Liu, W. Shen and J. Xue, “The Effect of Particle Size of Nanometer $\mathrm{ZrO}_{2}$ on the Tribolological Behavior of PEEK,” Wear, Vol. 198, 1996, pp. 216-219. doi:10.1016/0043-1648(96)07201-8

[33] Q. Wang, J. Xue, W. Shen and Q. Xue, “The Effect of Nanometer SiC Filler on the Tribological Behavior of PEEK,” Wear, Vol. 209, No. 1-2, 1997, pp. 316-321. doi:10.1016/S0043-1648(97)00015-X

[34] Q. Wang, Q. Xue and W. Shen, "The Friction and Wear Properties of Nanometre $\mathrm{SiO}_{2}$-Filled Polyetheretherketone, Tribology International, Vol. 30, No. 3, 1997, pp. 193-197. doi:10.1016/S0301-679X(96)00042-4

[35] Q. Wang, Q. Xue, W. Liu and J. Chen, “The Friction and Wear Characteristics of Nanometer SiC and Polytetrafluoroethylene-Filled Polyetheretherketone," Wear, Vol. 243, No. 1-2, 2000, pp. 140-146. doi:10.1016/S0043-1648(00)00432-4

[36] Q. Wang, Q. Xue, W. Liu and J. Chen, "Effect of Nanometer SiC Filler on the Tribological Behavior of PEEK under Distilled Water Lubrication,” Journal of Applied Polymer Science, Vol. 78, No. 3, 2000, pp. 609-614. doi:10.1002/1097-4628(20001017)78:3<609::AID-APP1 $\underline{60>3.0 . \mathrm{CO} ; 2-\mathrm{D}}$

[37] C. J. Schwartz and S. Bahadur, "Studies on the Tribological Behavior and Transfer Film-Counterface Bond Strength for Polyphenylene Sulfide Filled with Nanoscale Alumina Particles,” Wear, Vol. 237, No. 2, 2000, pp. 261273. doi:10.1016/S0043-1648(99)00345-2

[38] E. Petrovicova, R. Knight, L. S. Schadler and T. E. Twardowski, "Nylon 11/Silica Nanocomposite Coatings Applied by the HVOF Process, II. Mechanical and Barrier Properties,” Journal of Applied Polymer Science, Vol. 78, No. 13, 2000, pp. 2272-2289. doi:10.1002/1097-4628(20001220)78:13<2272::AID-AP P50>3.0.CO;2-U

[39] M. Avella, M. E. Errica and E. Martuscelli, "Novel PMMA/CaCO ${ }_{3}$ Nanocomposites Abrasion Resistant Prepared by an in Situ Polymerization Process,” Nano Letters, Vol. 1, No. 4, 2001, pp. 213-217. doi:10.1021/nl015518v

[40] L. Yu, S. Yang, H. Wang and Q. Xue, “An Investigation of the Friction and Wear Behaviors of Micrometer Copper Particle-Filled Polyoxymethylene Composites,” Journal of Applied Polymer Science, Vol. 77, No. 11, 2000, pp. 2404-2410. doi:10.1002/1097-4628(20000912)77:11<2404::AID-AP P8>3.0.CO;2-Q

[41] W. Sawyer, K. Freudenberg, P. Bhimaraj and L. Schadler, "A Study on the Friction and Wear Behavior of PTFE Filled with Alumina Nanoparticles,” Wear, Vol. 254, No. 5-6, 2003, pp. 573-580. doi:10.1016/S0043-1648(03)00252-7

[42] D. Burris and W. G. Sawyer, "Tribological Sensitivity of 
PTFE-Alumina Nanocomposites to a Range of Traditional Surface Finishes,” Tribology Transactions, Vol. 48, No. 2, 2005, pp. 1-7. doi:10.1080/05698190590923842

[43] M. Fuji, T. Takei, T. Watanabe and M. Chikazawa, "Effect of Wettability on Adhesion Force between Silica Particles Evaluated by Atomic Force Microscopy Measurement as a Function of Relative Humidity,” Langmuir, Vol. 15, No. 13, 1999, pp. 4584-4589. doi:10.1021/la981533c

[44] S. C. Chung, W. G. Hahm, S. S. Im and S. G. Oh, "Poly (Ethylene Terephthalate)(PET) Nanocomposites Filled with Fumed Silicas by Melt Compounding," Macromolecular Research, Vol. 10, No. 4, 2002, pp. 221-229. doi:10.1007/BF03218309

[45] J. W. Cho and D. R. Paul, "Nylon 6 Nanocomposites by Melt Compounding,” Polymer, Vol. 42, No. 3, 2001, pp. 1083-1094. doi:10.1016/S0032-3861(00)00380-3

[46] C. M. Liauw, P. Dumitru, G. C. Lees, M. L. Clemens and R. N. Rothon, "Interfacial Modification of Polystyreneblockpolybutadiene-Block-Polystyrene/Magnesium Hydroxide Composites, 1 Effect on Rheological Properties,” Macromolecular Materials and Engineering, Vol. 288, No. 5, 2003, pp. 412-420. doi:10.1002/mame.200390035

[47] C. M. Liauw, R. N. Rothon, G. C. Lees, P. Dumitru, Z. Iqbal, V. Khunova and P. Alexy, "Filler Surface Modification with Organic Acids and Derivatives,” Proceedings of Functional Effect Fillers, Berlin, 2000.

[48] S. H. Ahn, S. H. Kim and S. G. Lee, "Synthesis and Characterization of Soluble Polypyrrole with Improved Electrical Conductivity,” Journal of Applied Polymer Science, Vol. 84, No. 14, 2002, pp. 2583-2590. doi:10.1002/app.10281

[49] S. H. Ahn, S. H. Kim and B. C. Kim, "Mechanical Properties of Silica Nanoparticle Reinforced Poly (Ethylene 2, 6-Naphthalate), Macromolecular Research, Vol. 12, No. 3, 2004, pp. 293-302. doi:10.1007/BF03218403

[50] G. Decher, “Fuzzy Nanoassemblies: Toward Layered Polymeric Multicom-Posites, Science, Vol. 277, No. 5330, 1997, pp. 1232-1238. doi:10.1126/science.277.5330.1232

[51] W. F. Bradley, "The Structural Scheme of Attapulgite," American Mineralogist, Vol. 25, 1940, pp. 405-410.

[52] Y. H. Lai, M. C. Kuo, J. C. Huang and M. Chen, "Thermomechanical Properties of Nanosilica Reinforced PEEK Composites,” Key Engineering Materials, Vol. 351, 2007, pp. 15-20. doi:10.4028/www.scientific.net/KEM.351.15

[53] Y. B. Guo, D. G. Wang and S. W. Zhang, "Adhesion and friction of Nanoparticles/Polyelectrolyte Multilayer Films by AFM and Micro-Tribometer,” Tribology International, Vol. 44, No. 7-8, 2011, pp. 906-915. doi:10.1016/j.triboint.2011.03.007

[54] Q. B. Wang, M. L. Gao and S. W. Zhang, "Nanofriction Properties of Molecular Deposition Films," Science in China (Series B), Vol. 43, No. 2, 2003, pp. 12-14.

[55] P. Zhang, Q. Xue, Z. Du and Z. Zhang, "The Tribological Behavior of LB Films of Fatty Acids and Nanoparticles,” Wear, Vol. 242, No. 1-2, 2000, pp. 147-151. doi:10.1016/S0043-1648(00)00405-1

[56] P. Zhang, Q. Xue, Z. Du, et al., “The Tribological Behavior of Ordered System Ultrathin Films,” Wear, Vol.
254, No. 10, 2003, pp. 959-964. doi:10.1016/S0043-1648(03)00300-4

[57] G. T. Gu, Z. J. Zhang and H. X. Dang, "Preparation and Characterization of Hydrophobic Organic-Inorganic Composite Thin Films of PMMA/SiO $/ 2 \mathrm{TiO}_{2}$ with Low Friction Coefficient,” Applied Surface Science, Vol. 221, No. 1-4, 2004, pp. 129-135. doi:10.1016/S0169-4332(03)00865-1

[58] G. B. Yang, H. X. Ma, Z. S. Wu and P. Y. Zhang, "Tribological Behavior of ZnS-Filled Polyelectrolyte Multilayers,” Wear, Vol. 262, No. 3-4, 2007, pp. 471-476. doi:10.1016/j.wear.2006.06.018

[59] M. S. Barrios, L. V. F. Gonzalez, M. A. V. Rodriguez and J. M. M. Pozas, "Acid Activation of a Palygorskite with HCl: Development of Physico-Chemical, Textural and Surface Properties,” Applied Clay Science, Vol. 10, No. 3, 1995, pp. 247-258. doi:10.1016/0169-1317(95)00007-Q

[60] A. Corma, A. Misfud and E. Sanz, "Influence of the Chemical Composition and Textural Characteristics of Palygorskite on the Acid Leaching of Octahedral Cations,” Clay Minerals, Vol. 22, No. 2, 1987, pp. 225-232. doi:10.1180/claymin.1987.022.2.10

[61] C. N. Rhodes, M. Franks, G. M. B. Parkes and D. R. Brown, "The Effect of Acid Treatment on the Activity of Clay Supports for $\mathrm{ZnCl}_{2}$ Alkylation Catalysts,” Journal of the Chemical Society, Chemical Communications, Vol. 12, 1991, pp. 804-807. doi:10.1039/c39910000804

[62] S. Bahadur, "The Development of Transfer Layers and Their Role in Polymer Tribology,” Wear, Vol. 245, No. 1-2, 2000, pp. 92-99. doi:10.1016/S0043-1648(00)00469-5

[63] T. Suwa, M. Takehisa and S. Machi, "Melting and Crystallization Behavior of Poly (Tetrafluoroethylene). New Method for Molecular Weight Measurement of Poly (Tetrafluoroethylene) Using a Differential Scanning Calorimeter," Journal of Applied Polymer Science, Vol. 17, No. 11, 1973, pp. 3253-3257. doi:10.1002/app.1973.070171102

[64] I. A. Ovid'Ko, “Deformation of Nanostructures,” Science, Vol. 295, No. 5564, 2002, pp. 2382-2386.

[65] Q. H. Wang and Q. J. Xue, "Wear Mechanisms of Polyetheretherketone Composites Filled with Various Kinds of SiC,” Wear, Vol. 213, No. 1-2, 2007, pp. 54-58.

[66] F. H. Su, Z. Z. Zhang, K. Wang, W. Jiang and W. M. Liu, "Friction and Wear Properties of Carbon Fabric Composites Filled with Nano- $\mathrm{Al}_{2} \mathrm{O}_{3}$ and Nano-Si $\mathrm{N}_{4}$," Journal of Composites Part A: Applied Science and Manufacturing, Vol. 37, No. 9, 2006, pp. 1351-1357. doi:10.1016/j.compositesa.2005.08.017

[67] E. Chabert, M. Bornert, E. Bourgeat-Lami, J. Y. Cavaille and C. Dendievel, "Filler-Filler Interactions and Viscoelastic Behavior of Polymer Nanocomposites," Materials Science and Engineering: A, Vol. 381, No. 1-2, 2004, pp. 320-330. doi:10.1016/j.msea.2004.04.064

[68] F. H. Su, Z. Z. Zhang and W. M. Liu, "Study on the Friction and Wear Properties of Glass Fabric Composites Filled with Nano- and Micro-Particles under Different Conditions.” Materials Science and Engineering: A, Vol. 
392, No. 1-2, 2005, pp. 359-365.

doi:10.1016/j.msea.2004.09.036

[69] K. Friedrich, Z. Zhang and P. Klein, "Wear of Polymercomposites,” In: P. Sydenham and R. Thorn, Eds., Handbook of Measuring System Design, John Wiley \& Sons, Hoboken, 2005.

[70] J. Bijwe J. J. Rajesh A. Jeyakumar, A. Ghosh and U. S. Tewari, "Influence of Solid Lubricants and Fiber Reinforcement on Wear Behavior of Polyethersulphone," Tribology International, Vol. 33, No. 10, 2000, pp. 697-706. doi:10.1016/S0301-679X(00)00104-3

[71] J. Wang, M. Gua, S. Bai and S. Ge, "Investigation of the Influence of $\mathrm{MoS}_{2}$ Filler on the Tribological Properties Ofcarbon Fiber Reinforced Nylon 1010 Composites,” Wear, Vol. 255, No. 1-6, 2003, pp. 774-779. doi:10.1016/S0043-1648(03)00268-0

[72] J. Bijwe V. Naidu, N. Bhatnagar and M. Fahim, "Optimum Concentration of Reinforcement and Solid Lubricant Tinpolyamide 12 Composites for Best Tribo-Performance in Two Wear Modes," Tribology Letters, Vol. 21, 2006, pp. 59-66.

[73] X. R. Zhang, X. Q. Pei and Q. H. Wang, "Effect of Solid lubricant on Thetribological Properties of Polyimide Com- posites Reinforced with Carbon Fibers,” Journal of Reinforced Plastics and Composites, Vol. 27, No. 18, 2009, pp. 2005-2012. doi:10.1177/0731684408090718

[74] M. H. Cho and S. Bahadur, "Study of the Tribological Synergistic Effects in CuO-Filled and Fiber-Reinforced Polyphenylenesulfide Composites,” Wear, Vol. 258, No. 5-6, pp. 835-845. doi:10.1016/j.wear.2004.09.055

[75] Z. Zhang, C. Breidt, L. Chang, F. Haupert and K. Friedrich, "Enhancement of the Wear Resistance of Epoxy: Short Carbon Fiber, Graphite, PTFE and Nano-TiO ${ }_{2}$ " Composites Part A, Vol. 35, No. 12, 2004, pp. 1385-1392. doi:10.1016/j.compositesa.2004.05.005

[76] L. Chang, Z. Zhang, C. Breidt and K. Friedrich, "Tribological Properties of Epoxy Nanocomposites: I. Enhancement of the Wear Resistance by Nano-TiO ${ }_{2}$ Particles,” Wear, Vol. 258, No. 1-4, pp. 141-148. doi:10.1016/j.wear.2004.09.005

[77] Q. Guo, M. Z. Rong, G. L. Jia, K. T. Lau and M. Q. Zhang, "Sliding Wear Performance of Nano-SiO ${ }_{2} /$ Short Carbon Fiber/Epoxy Hybrid Composites,” Wear, Vol. 266, No. 7-8, 2009, pp. 658-665. doi:10.1016/j.wear.2008.08.005 